\title{
Local quasigeoid modelling in Slovakia using the finite volume method on the discretized Earth's topography
}

\author{
Róbert ČUNDERLÍK* (1), Matej MEDL'A (1), Karol MIKULA (1) \\ Department of Mathematics and Descriptive Geometry, Faculty of Civil Engineering, \\ Slovak University of Technology, Radlinského 11, 81368 Bratislava, Slovak Republic
}

\begin{abstract}
The paper presents local quasigeoid modelling in Slovakia using the finite volume method (FVM). FVM is used to solve numerically the fixed gravimetric boundary value problem (FGBVP) on a 3D unstructured mesh created above the real Earth's surface. Terrestrial gravimetric measurements as input data represent the oblique derivative boundary conditions on the Earth's topography. To handle such oblique derivative problem, its tangential components are considered as surface advection terms regularized by a surface diffusion. The FVM numerical solution is fixed to the GOCE-based satelliteonly geopotential model on the upper boundary at the altitude of $230 \mathrm{~km}$. The horizontal resolution of the $3 \mathrm{D}$ computational domain is $0.002 \times 0.002 \mathrm{deg}$ and its discretization in the radial direction is changing with altitude. The created unstructured $3 \mathrm{D}$ mesh of finite volumes consists of 454,577,577 unknowns. The FVM numerical solution of FGBVP on such a detailed mesh leads to large-scale parallel computations requiring $245 \mathrm{~GB}$ of internal memory. It results in the disturbing potential obtained in the whole $3 \mathrm{D}$ computational domain. Its values on the discretized Earth's surface are transformed into the local quasigeoid model that is tested at 404 GNSS/levelling benchmarks. The standard deviation of residuals is $2.8 \mathrm{~cm}$ and decreases to $2.6 \mathrm{~cm}$ after removing 9 identified outliers. It indicates high accuracy of the obtained FVM-based local quasigeoid model in Slovakia.
\end{abstract}

Key words: local quasigeoid modelling, fixed gravimetric boundary-value problem, finite volume method, unstructured computational mesh, GNSS-levelling test

\section{Introduction}

Detailed terrestrial gravimetric mapping in Slovakia accomplished during the last 6 decades (Zahorec et al., 2017b) has brought valuable information about the gravity field in this region. Thanks to a very dense distribution of gravimetric measurements, the precise local quasigeoid modelling

\footnotetext{
*corresponding author: e-mail: robert.cunderlik@stuba.sk
} 
in Slovakia has been dominantly based on the so-called gravimetric methods, i.e. on solving different types of the geodetic boundary value problems (GBVP). The first local quasigeoid models were obtained using the well known remove-compute-restore strategy, cf. Mojzeš and Janák, (1999), Mojzeš et al. (2006), Valko et al. (2008). Later on, new approaches based on numerical methods like the boundary element method (BEM), finite element method (FEM) or finite volume method (FVM) have been developed and applied for local quasigeoid modelling in Slovakia, e.g. Čunderlik et al. (2008), Fašková et al. (2010), Macák et al. (2015), Medl'a et al. (2018). Recently, an approach based on a combination of spherical harmonics, band-limited spherical radial basis functions and the residual terrain model technique has resulted in the most precise local quasigeoid model in Slovakia (Bucha et al., 2016).

In this paper we apply a newly developed FVM approach to the local quasigeoid modelling in Slovakia with an aim to reach similar 'cm-level' accuracy. This approach is based on FVM on 3D unstructured meshes above the real Earth's topography (Medl'a et al., 2018) and the oblique derivative boundary condition is treated in the way that its tangential component is considered as an advection along the Earth's topography regularized by a carefully designed surface diffusion term (Droniou et al., 2019). This has an obvious advantage that the FVM numerical solution to GBVP is computed directly on the discretized Earth's surface. To obtain such a numerical solution as precise as possible, a computational domain requires its discretization with high resolution while leading to large-scale parallel computations.

Section 2 presents the fixed gravimetric boundary-value problem and its "satellite-fixed" modification. To solve such a problem numerically, main ideas of the applied FVM approach are briefly introduced while referring to (Droniou et al., 2019), where a detailed mathematical background is published. Section 3 describes a $3 \mathrm{D}$ computational domain and input data considered as boundary conditions. Section 4 briefly comments computational aspects of the large-scale parallel computations performed on the parallel cluster. Section 5 presents the obtained FVM numerical solution transformed into the local quasigeoid model in Slovakia. Here its precision is validated by the GNSS/levelling test. Finally, Section 6 summarizes main conclusions. 


\section{FVM for the linearized fixed gravimetric boundary-value problem}

The linearized fixed gravimetric boundary-value problem (FGBVP) represents an exterior oblique derivative problem for the Laplace equation. It is defined as (cf. Koch and Pope, 1972; Bjernhammar and Svensson, 1983; Grafarend, 1989):

$$
\begin{array}{ll}
\nabla^{2} T(\mathbf{x})=0 & \mathbf{x} \in \Re^{3}-E, \\
\langle\nabla T(\mathbf{x}), \mathbf{s}(\mathbf{x})\rangle=-\delta g(\mathbf{x}) & \mathbf{x} \in \Gamma, \\
T(\mathbf{x})=O(\mathbf{x})^{-1} & \mathbf{x} \rightarrow \infty,
\end{array}
$$

where $T$ is the disturbing potential (as a difference between the actual gravity potential $W$ and the normal gravity potential $U$ ) at any point $\mathbf{x}$, and $\delta g$ is the gravity disturbance. The domain $E$ represents the body of the Earth with its boundary $\Gamma$ given by the Earth's surface. $\langle\nabla T, \mathbf{s}\rangle$ is the inner product of two vectors $\nabla T$ and $\mathbf{s}$, where the unit vector $\mathbf{s}$ is defined as:

$\mathbf{s}(\mathbf{x})=-\frac{\nabla U(\mathbf{x})}{|\nabla U(\mathbf{x})|} \quad \mathbf{x} \in \Gamma$.

Eq. (2) represents the oblique derivative boundary condition (BC) as the normal to the Earth's surface $\Gamma$ does not coincide with the vector $\mathbf{s}$ defined in Eq. (4).

Although the FGBVP (1)-(3) deals with the infinite domain, in the presented FVM approach we restrict our computations only to a bounded domain $\Omega$ constructed by artificial boundaries (Fig. 1a). The bottom boundary $\Gamma_{\text {local }}$ is given by a part of the Earth's surface in the area of interests while considering its real topography. An artificial upper boundary is chosen at a mean altitude of the GOCE satellite orbits, where the Dirichlet-type BC are prescribed in the form of the disturbing potential $T^{S A T}$ that can be generated from some GOCE-based satellite-only geopotential model. On four side boundaries, the Dirichlet-type BC are prescribed as well. In this bounded computational domain we consider the linearized FGBVP in the form:

$\nabla^{2} T(\mathbf{x})=0 \quad \mathbf{x} \in \Omega$, 


$$
\begin{array}{ll}
\langle\nabla T(\mathbf{x}), \mathbf{s}(\mathbf{x})\rangle=-\delta g(\mathbf{x}) & \mathbf{x} \in \Gamma_{\text {local }}, \\
T(\mathbf{x})=T^{S A T}(\mathbf{x}) & \mathbf{x} \in \partial \Omega-\Gamma_{\text {local }} .
\end{array}
$$

Such a "satellite-fixed" modification of the original FGBVP (1)-(3) is based on fixing the solution on the upper and side boundaries, i.e. the regularity condition at infinity in Eq. (3) is not considered.

On the 3D domain $\Omega$ above the discretized Earth's topography we construct an optimal computational grid using an evolving surface method (Medl'a et al., 2018). Here the discretized bottom boundary $\Gamma_{\text {local }}$ is evolved through the 3D computational domain until the chosen upper boundary. The evolving surfaces are then combined to construct a hexahedral mesh (Fig. 1b).

a)

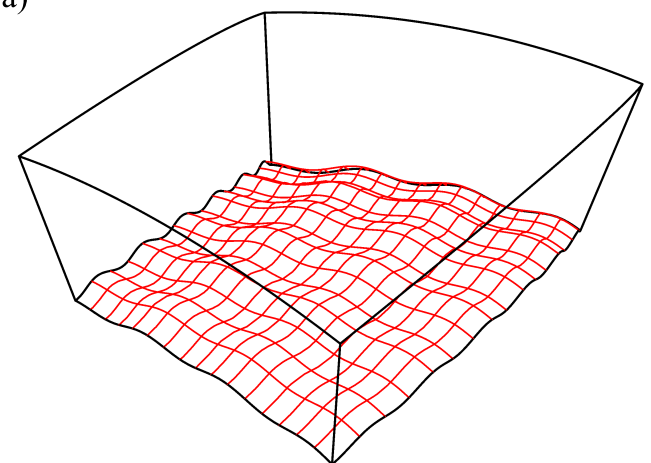

b)

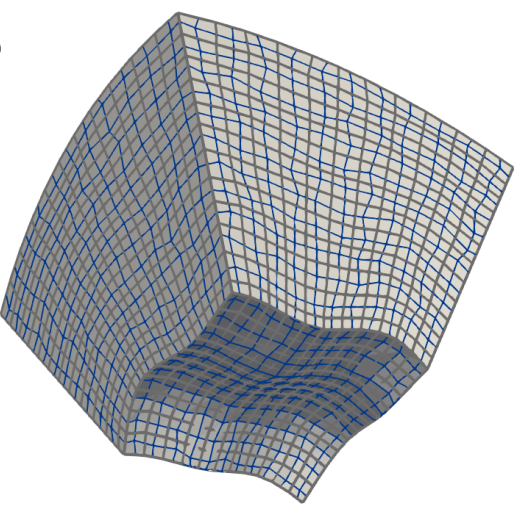

Fig. 1. a) Sketch of a computational domain, and b) its discretization by a hexahedral mesh.

On such a 3D unstructured mesh, a generic finite volume approximation of FGBVP has been developed in (Droniou et al., 2019). Its "advectiondiffusion form" along the boundary, see formula (19a) in Section 2 of (Droniou et al., 2019) is used for all computations presented in this paper. Such FVM discretization is based on recasting of the model to transform the oblique derivative into a normal derivative, handled as the Neumann boundary condition, and a boundary advection term along $\Gamma_{\text {local }}$. The boundary advection term is treated by a second-order central approximation and regularized by a small amount of diffusion along $\Gamma_{\text {local }}$ proportional to a bottom boundary discretization step $h$. Such "advection-diffusion approach" is sta- 
bilizing otherwise a second-order central approximation of the surface advection. For such FVM, the rigorous theory has been established in (Droniou et al., 2019) showing a convergence of the numerical solution to the analytical solution of FGBVP as well as estimates of the error between the numerical and analytical solutions. The method is generic in that sense that it allows to choose different approximations of diffusion fluxes inside the domain, for solving the Laplace equation, and on the boundary, for treatment of the oblique derivative, under the broad consistency and coercivity assumptions. For computations presented in this paper we chose the fluxes specified in detail in Section 3.1 of (Droniou et al., 2019).

\section{Computational domain and input data}

The aforementioned FVM approach has been applied for local gravity field modelling in the area of Slovakia. Our computational domain has been bounded by the Earth's topography as a bottom boundary, by an upper boundary chosen at the altitude of $230 \mathrm{~km}$ above the reference ellipsoid, which represents a mean altitude of the GOCE satellite orbits, and by 4 side boundaries (see the sketch on Fig. 1a). Such a computational domain has been discretized into finite volumes using the approach introduced in Medl'a et al. (2018). To reduce large memory requirements, the radial dimension of finite volumes has been changing with increasing altitude. Hence, the radial size of finite volumes close to the Earth's topography has been almost 6 times smaller than those on to the upper boundary.

In our numerical experiment we have considered the Earth's topography with the horizontal resolution $0.002 \times 0.002 \mathrm{deg}$ (latitude $\times$ longitude), which represents approximately $200 \times 200 \mathrm{~m}$. Figure 2 depicts such a detail consideration of the Earth's topography. At the grid nodes on the bottom boundary, the gravity disturbances as the oblique derivative $\mathrm{BC}$ have been prescribed (Fig. 3). Inside Slovakia, they have been generated from the detailed map of the Complete Bouguer Anomalies (Pašteka et al., 2017) using the CBA2G software (Marušiak et al., 2015) and a detailed digital terrain model. In this process precise modelling of terrain corrections plays a crucial role, c.f. Majkráková et al. (2016) or Zahorec et al. (2017a). In this way all information from the detailed terrestrial gravimetric mapping in Slovakia (Zahorec et al., 2017b) has been incorporated into the input data. 


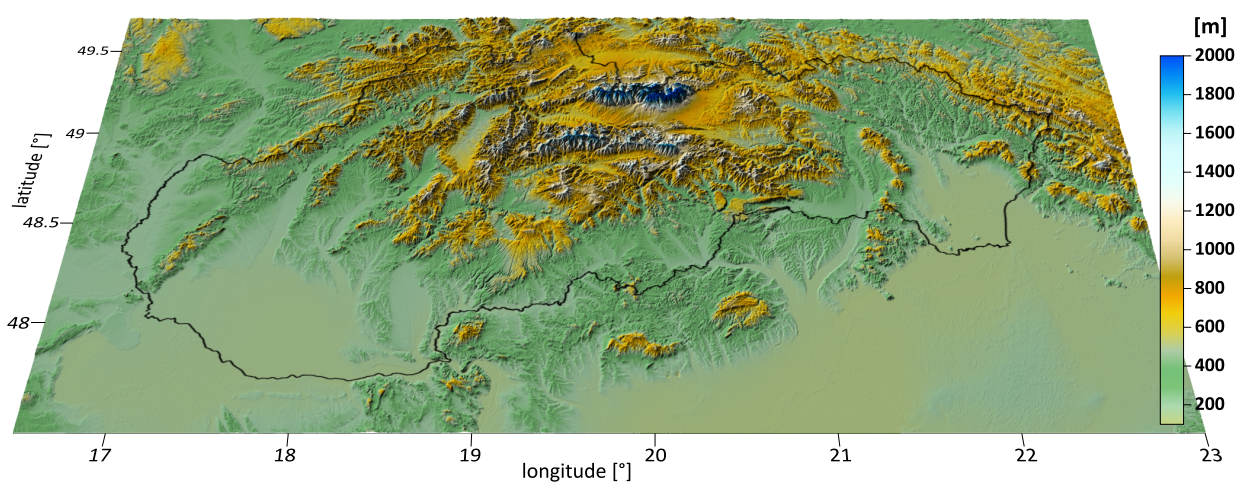

Fig. 2. The Earth's topography in area of Slovakia as a bottom boundary of the computational domain (the horizontal resolution: $0.002 \times 0.002 \mathrm{deg}$ ).

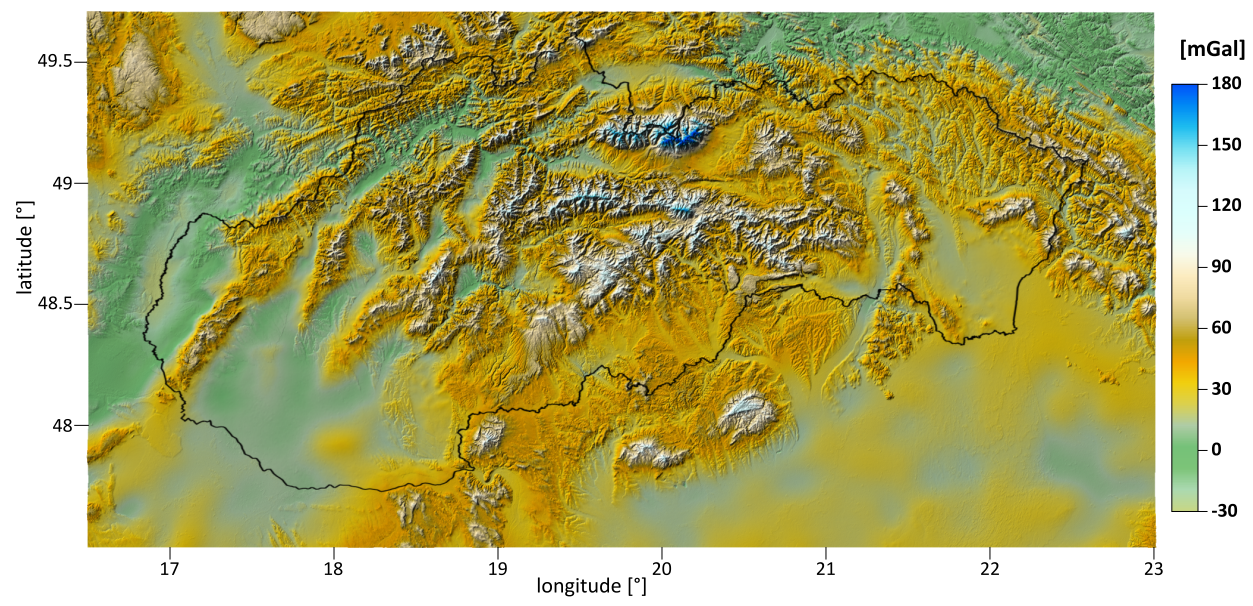

Fig. 3. Gravity disturbances on the Earth's topography as the oblique derivative BC on the bottom boundary.

Outside Slovakia, the gravity disturbances have been interpolated from the GGMPlus database (Hirt et al., 2013).

On the upper boundary at the altitude of $230 \mathrm{~km}$ above the reference ellipsoid, the Dirichlet $\mathrm{BC}$ has been prescribed in the form of disturbing potential (Fig. 4). It has been generated from the satellite-only geopotential model, namely GO_CONS_GCF_2_DIR_R5 up to d/o 300 (Bruinsma et al., 2013). On 4 side boundaries, the Dirichlet BC has been prescribed as 


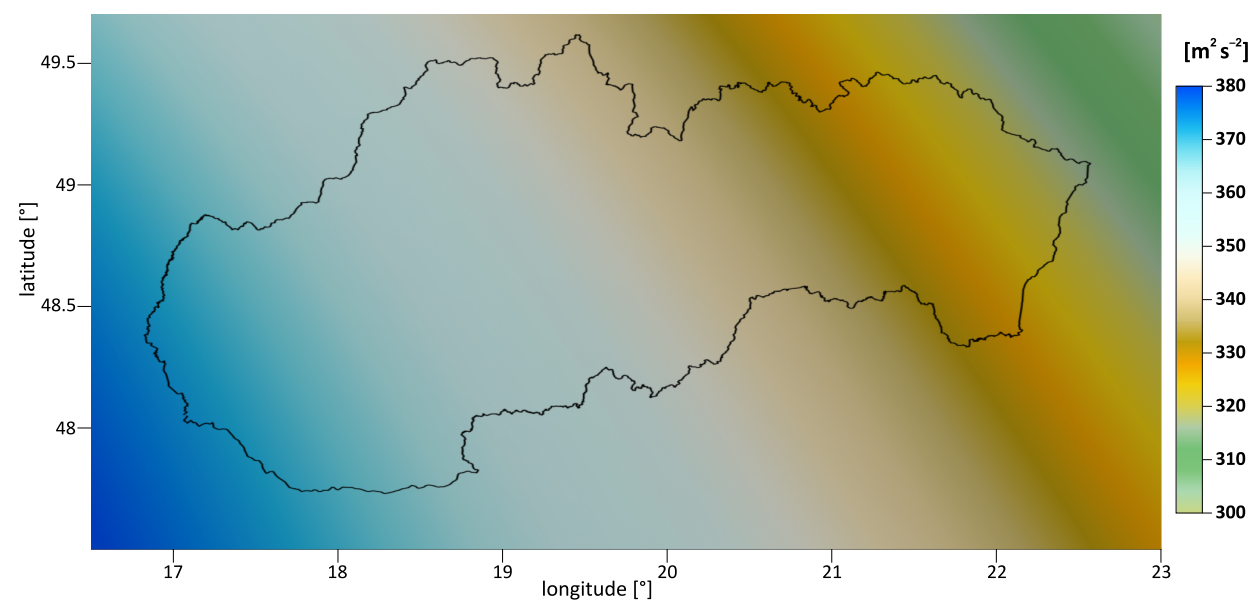

Fig. 4. Disturbing potential at the altitude of $230 \mathrm{~km}$ above the reference ellipsoid as the Dirichlet BC on the upper boundary generated from the GO_CONS_GCF_2_DIR_R5 model.

well. However, here the disturbing potential has been generated from the EIGEN-6C4 geopotential model up to d/o 2160 (Förste et al., 2014). Due to the fact that the side boundaries have been chosen quite close to the borders of Slovakia, the prescribed disturbing potential could not be generated purely from satellite-only models. Otherwise it would badly influence our numerical solution close to the side boundaries, especially on the Earth's surface.

As mentioned above, a discretization of the computational domain in the radial direction has depended on altitude. We have divided the radial dimension into 126 parts. The size of finite volumes in the radial direction has been about $250 \mathrm{~m}$ for those on the Earth's surface while exceeding $1 \mathrm{~km}$ for those on the upper boundary. To consider such non-uniform division is quite natural taking into account that the gravity field becomes smother and smoother with increasing altitude.

Finally, the computational domain has been discretized into the 3D unstructured mesh of finite volumes which has consisted of $3,251 \times 1,101 \times$ 127 (longitude $\times$ latitude $\times$ height $)=454,577,577$ unknowns in the whole computational domain $(3,579,351$ on the discretized Earth's topography). 


\section{Computational aspects}

A numerical solution of FGBVP on such a 3D unstructured mesh using the developed FVM approach has required about 245 GB of the internal memory. Therefore, we were able to perform large-scale computations on one node of our cluster with 256 GB RAM and 32 cores. Thanks to its NUMA architecture, the parallelization has been performed using multithreading and the OpenMP standard. The final large-scale computations took about $77 \mathrm{~h}$ of the CPU time ( $\sim 3.2$ days). Such relatively high computational time was partly caused by a slow convergence of the BiCGSTAB linear solver for such a detailed consideration of the Earth's topography, and partly by too sensitive tolerance as a stopping criterion.

\section{Local quasigeoid model in Slovakia and its validation}

The numerical solution of FGBVP using the FVM approach has resulted in the disturbing potential obtained in the whole computational domain. To obtain a local quasigeoid model, we have focused on the obtained solution on the bottom boundary, i.e. at the points directly on the Earth's surface (Fig. 2). Here the obtained disturbing potential $T$ has been transformed into the quasigeoidal heights $\zeta$ using the formula:

$\varsigma_{i}=h_{i}-H_{i}^{\text {norm }}=h_{i}-\frac{-\left(T_{i}+U_{i}-W_{0}\right)}{\gamma_{i}}$,

where $h$ is the ellipsoidal height, $H^{\text {norm }}$ denotes the normal height, $U$ is the normal potential evaluated at the $i$-th grid point on the Earth's surface, $\gamma$ is a mean value of the normal gravity between the quasigeoid and the Earth's surface at this point, and $W_{0}$ represents a reference value of the geopotential adopted for a realization of the International Height Reference System (IHRS) (Sánchez et al., 2016). Parameters of the normal gravity filed have been computed from the WGS-84 reference ellipsoid. In this way the quasigeoidal heights have been expressed with respect to the WGS-84 reference ellipsoid and to the $W_{0}$ value adopted for IHRS.

Figure 5 depicts the obtained local quasigeoid model in Slovakia. Its resolution is $0.002 \times 0.002 \mathrm{deg}$ (approximately $200 \times 200 \mathrm{~m}$ ). To validate its precision, the GNSS/levelling test has been performed at 404 benchmarks. 


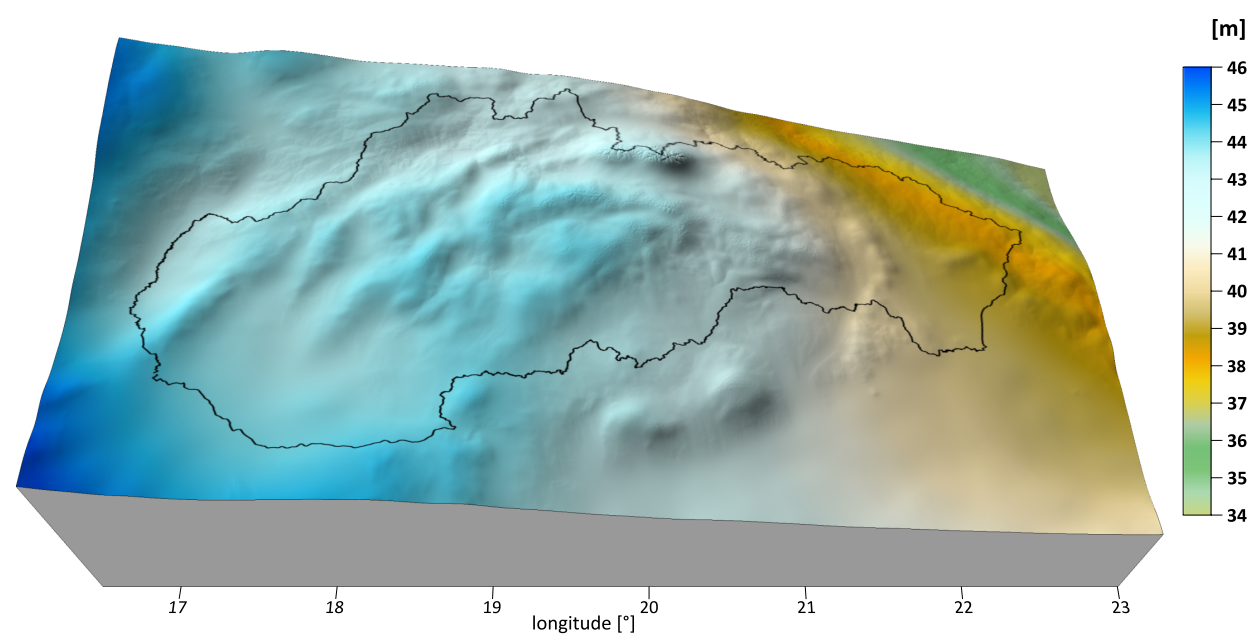

Fig. 5. Local quasigeoid model in Slovakia as the FVM numerical solution of FGBVP (the horizontal resolution: $0.002 \times 0.002 \mathrm{deg}$ ).

Figure 6 depicts the obtained residuals. Their statistics is summarized in Table 1. The local quasigeoid model is also compared with DVRM05 (Digital Vertical Reference Model), which is currently an official model in Slovakia to transform ellipsoidal heights (determined by GNSS in the ETRS89 system) into sea level heights, namely into the normal heights in the Bpv system (http://www.geoportal.sk). This model was developed by polynomial fitting of a gravimetric-only quasigeoid to $304 \mathrm{GNSS} /$ levelling benchmarks of the National Spatial Network of Slovakia (Klobušiak et al., 2005). Consequently, differences between both models depicted in Figure 7 show how the "GNSS-levelling quasigeoid" differs from our gravimetric-only quasigeoid. When overlapping both figures (Fig. 8a), one can see a nice agreement except several points, where the colours are significantly different. These benchmarks have been identified as outliers (depicted in black in Fig. 8b). Statistics of the GNSS/levelling test excluding these 9 outliers is presented in Table 1.

Differences between the obtained local quasigeoid model and DVRM05 depicted in Figure 7 are affected by two main aspects: 1) by accuracy of the GNSS/levelling benchmarks that include errors of the precise 3D positioning by GNSS as well as of precise levelling, and 2) by differences between our FVM solution and the original gravimetric-only quasigeoid used for develop- 


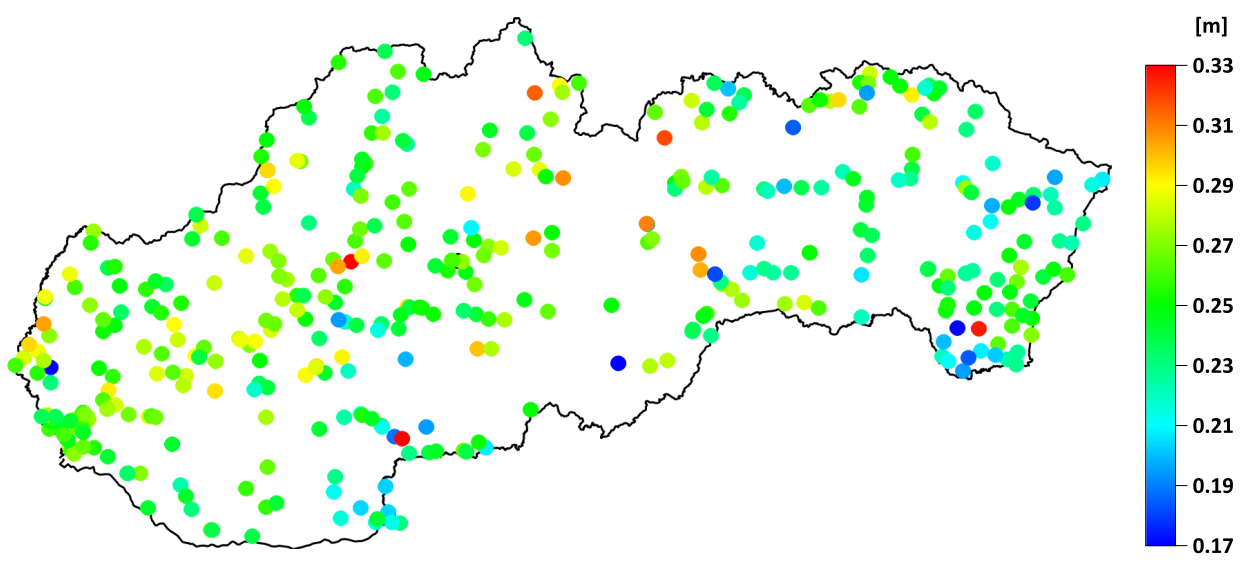

Fig. 6. GNSS/levelling test of the local quasigeoid model in Slovakia at 404 benchmarks.

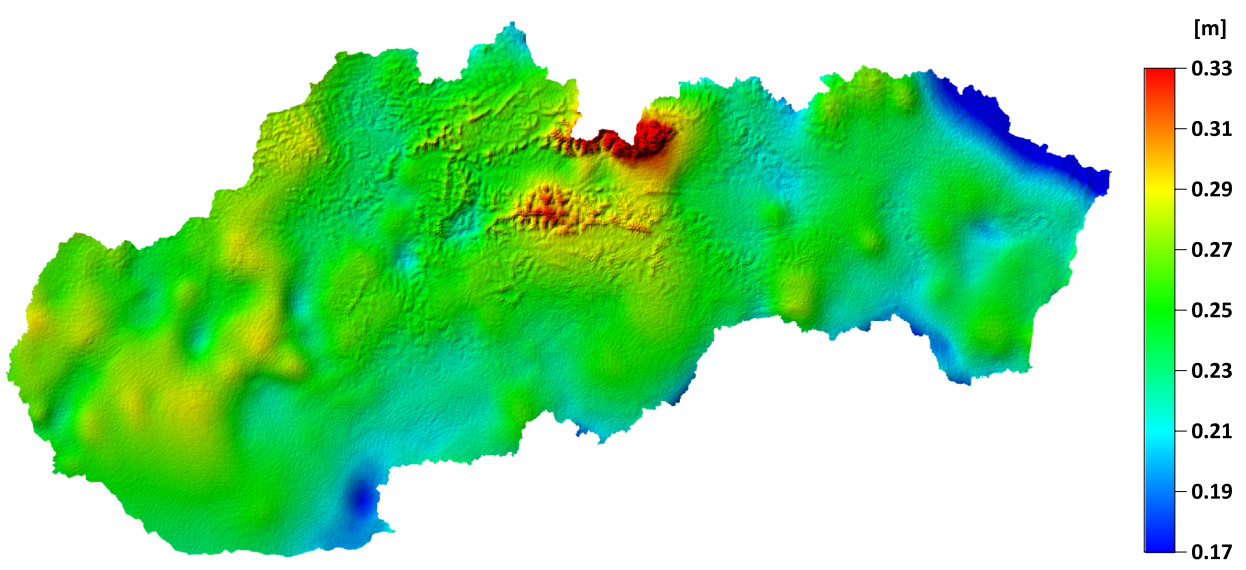

Fig. 7. Differences between the obtained local quasigeoid model in Slovakia and DVRM05.

ing the DVRM05 model. It is evident that our solution makes considerably higher undulation in the areas of our highest mountains, especially in High and Low Tatras. Here the residuals at two 'highest' GNSS/levelling benchmarks, namely 'Skalnaté Pleso (1772 m)' and 'Králova hol'a (1936 m)', are quite significant (in orange colour, see Fig. 8a). They indicate too high undulation in this mountainous region. On the other hand, accuracy of normal heights can be here of lower quality due to the complicated precise levelling, 

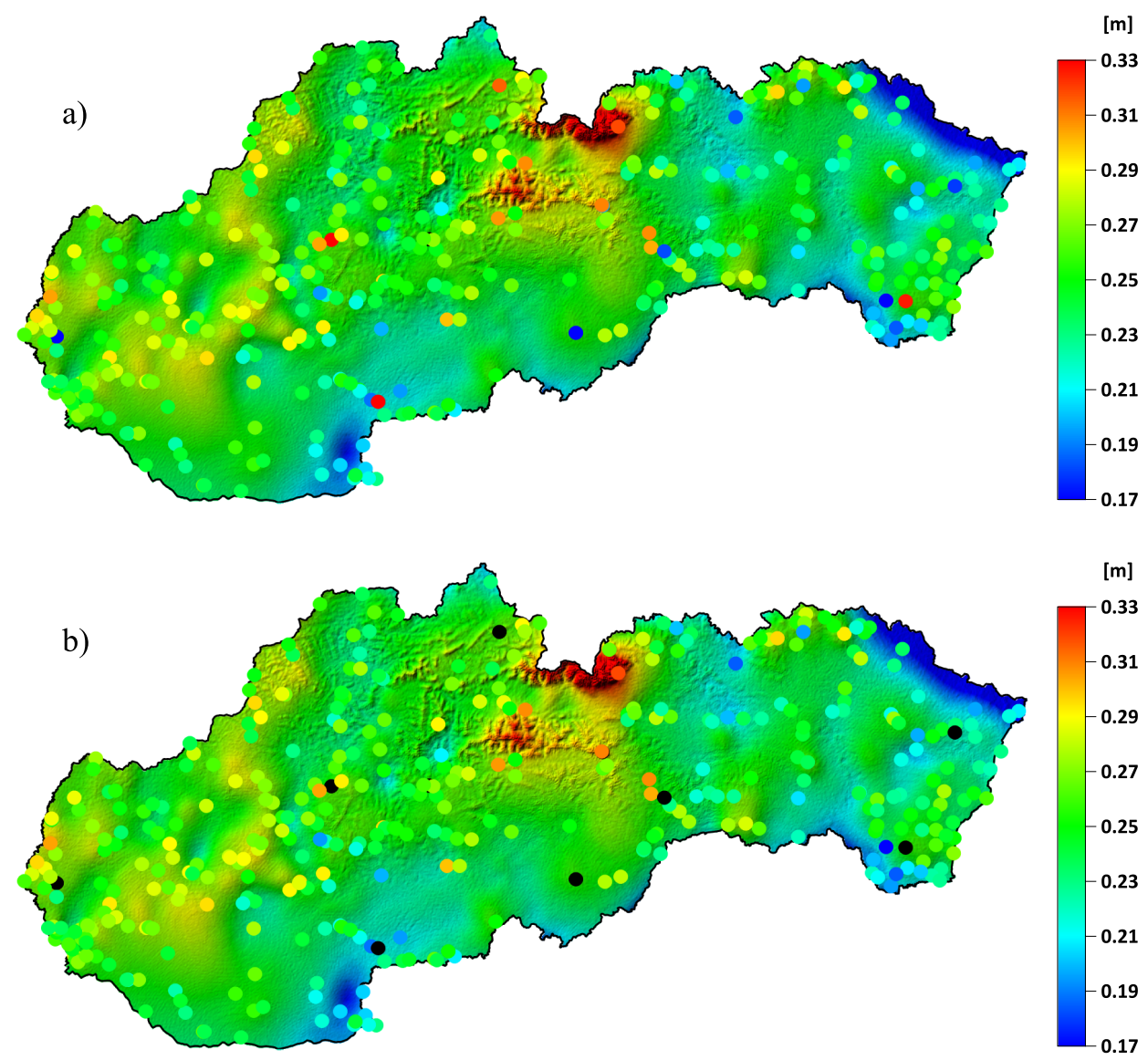

Fig. 8. a) Overlapping the residuals at GNSS/levelling benchmarks with differences between the obtained local quasigeoid model and DVRM05, b) the same without outliers depicted in black.

therefore it is difficult to estimate real accuracy of the obtained quasigeoid undulation.

Analysing the residuals, one can also detect a small but significant tilt from west to east (about few $\mathrm{cm}$ ). Slightly higher positive residuals dominate in the western part of Slovakia, while in the eastern Slovakia negative tendencies are visible, especially close to the borders with Poland and Hungary. This can be probably due to a lack of terrestrial gravimetric data 
Table 1. Statistics of the GNSS/levelling test.

\begin{tabular}{|c|c|c|}
\hline Characteristic & For all points & Without outliers \\
\hline Number of points & 404 & 395 \\
\hline Minimum & $0.131 \mathrm{~m}$ & $0.147 \mathrm{~m}$ \\
\hline Maximum & $0.352 \mathrm{~m}$ & $0.352 \mathrm{~m}$ \\
\hline Range & $0.221 \mathrm{~m}$ & $0.205 \mathrm{~m}$ \\
\hline Mean & $0.231 \mathrm{~m}$ & $0.231 \mathrm{~m}$ \\
\hline Median & $0.230 \mathrm{~m}$ & $0.230 \mathrm{~m}$ \\
\hline Standard deviation & $0.028 \mathrm{~m}$ & $0.026 \mathrm{~m}$ \\
\hline
\end{tabular}

from neighbouring countries. On the other side, the detected tilt can also indicate some systematic tendencies in the vertical levelling network in Slovakia.

A mean value and median of the residuals of the GNSS/levelling test is 23.1 and $23.0 \mathrm{~cm}$, respectively (Table 1 ). They indicate an offset of the national vertical datum of Slovakia with respect to $W_{0}=62,636,853.4 \mathrm{~m}^{2} \mathrm{~s}^{-2}$ adopted as a reference value for a realization of IHRS (Sánchez et al., 2016). Remark: the statistics in Table 1 includes corrections of the normal heights from the mean-tide into tide-free system. In Figures 6 and 8 these corrections are not considered in order to have consistent values with the differences depicted in Figure 7.

Finally we can state that the GNSS/levelling test indicates high precision of the obtained local quasigeoid model. Comparing with the previous quasigeoid models in Slovakia, it has outperformed all versions developed before 2016, and it is of a very similar quality as the recent one obtained by a completely different approach, namely by a combination of spherical harmonics, band-limited spherical radial basis functions and the residual terrain model technique (Bucha et al., 2016). Our approach based on the local gravity field modelling in spatial domain using FVM on the unstructured 3D mesh above the real Earth's topography has resulted in the quasigeoid model whose accuracy is about $2.8 \mathrm{~cm}$ and after excluding evident outliers $2.6 \mathrm{~cm}$ (Table 1). Taking into account that the GNSS/levelling benchmarks considered in our validation include also errors of the precise GNSS 3D positioning and precise levelling, which can exceed several $\mathrm{cm}$ especially in high mountainous regions, such accuracy confirms high efficiency of the applied FVM approach. 


\section{Conclusions}

The local quasigeoid model in Slovakia has been obtained by a numerical solution to the linearized FGBVP, namely to its "satellite-fixed" modification. For this purpose the developed generic FVM has been applied in the 3D computational domain above the real Earth's surface while solving the problem in spatial domain. Here the numerical solution has been fixed on the upper and side boundaries by the Dirichlet BC. In this way information from the GRACE/GOCE gravitational models have been incorporated into the FVM solution. Such a consideration essentially differs from the classical approaches based on the remove-compute-restore strategy that are usually used for local gravity field modelling.

On the discretized Earth's surface as a bottom boundary, terrestrial gravimetric measurements have been used as the oblique derivative BC. It is worth to remind that they are fully independent from the satellite data. The FVM discretization on the Earth's topography has been based on recasting of the model to transform the oblique derivative into a normal derivative and boundary advection term along the Earth's topography regularized by a carefully designed surface diffusion term (Droniou et al., 2019). The numerical experiment has shown that such a treatment of the oblique derivative problem has iteratively converged, even in the complicated Earth's topography of highest mountains like High Tatras. Although the quasigeoid undulation is here considerably higher in comparison with the official DVRM05 model, reliability of few GNSS/levelling benchmarks in this mountainous region is so far not sufficient to confirm, which quasigeoid model is closer to reality. On the other hand, GNSS/levelling test in other regions, mainly in lowland areas, could indicate some 'systematic tendencies' of the vertical levelling network in Slovakia.

An obvious advantage of the presented approach is that the FVM numerical solution to FGBVP has been obtained directly at points on the discretized Earth's surface. However, to get a solution as precise as possible, the 3D computational domain has required its discretization with high resolution. In our numerical experiment the horizontal resolution has been $0.002 \times 0.002 \mathrm{deg}$ and the discretization in the radial direction has been changing with altitude. The final unstructured 3D mesh of finite volumes has consisted of 454,577,577 unknowns. This has led to large-scale parallel computations requiring $245 \mathrm{~GB}$ of internal memory. As a result, the dis- 
turbing potential has been obtained in the whole 3D computational domain. Hence, different quantities of the local gravity field like the first derivatives (gravity disturbances and deflections of vertical) or the second derivatives (disturbing gravity gradients) can be derived at different altitudes of the 3D computational mesh. Such outcomes can be also useful for geophysical applications.

The disturbing potential on the discretized Earth's surface has been transformed into the local quasigeoid model in Slovakia. Its accuracy has been tested at 404 GNSS/levelling benchmarks. The standard deviation of residuals $2.8 \mathrm{~m}$, which has decreased into $2.6 \mathrm{~cm}$ after excluding 9 identified outliers, indicates its high accuracy. It is very similar as the accuracy of the recent local quasigeoid model obtained by a completely different approach (Bucha et al., 2016). It shows that local gravity field modelling based on a numerical solution of the problem in spatial domain using the developed FVM approach can reach the same quality as the state-of-the-art approaches nowadays used in physical geodesy.

Acknowledgements. Funded by the Government of Slovakia through an ESA Contract under the PECS (Plan for European Cooperating States), namely through the PECS contract SK2-08: "GOCE-based high-resolution gravity field modelling in a space domain (GOCE-numerics)". The view expressed herein can in no way be taken to reflect the official opinion of the European Space Agency. This work was also supported by the Grants APVV-15-0522 and VEGA 1/0486/20. We would also like to thank Juraj Papčo (STU Bratislava) for generating the surface gravity disturbances at grid points in Slovakia and the Geodetic and Cartographic Institute Bratislava for providing the GNSS/levelling data.

\section{References}

Bjerhammar A., Svensson L., 1983: On the geodetic boundary-value problem for a fixed boundary surface-A satellite approach. Bull. Géod., 57, 1-4, 382-393, doi: 10.10 07/BF02520941.

Bruinsma S. L., Förste C., Abrikosov O., Marty J.-C., Rio M.-H., Mulet S., Bonvalot S., 2013: The new ESA satellite-only gravity field model via the direct approach. Geophys. Res. Lett., 40, 14, 3607-3612, doi : 10.1002/grl.50716.

Bucha B., Janák J., Papčo J., Bezděk A., 2016: High-resolution regional gravity field modelling in a mountainous area from terrestrial gravity data. Geophys. J. Int., 207, 2, 949-966, doi: 10.1093/gji/ggw311. 
Čunderlík R., Mikula K., Mojžeš M., 2008: Numerical solution of the linearized fixed gravimetric boundary-value problem. J. Geod., 82, 1, 15-29, doi: 10.1007/s00190 -007-0154-0.

Droniou J., Medla M., Mikula K., 2019: Design and analysis of finite volume methods for elliptic equations with oblique derivatives; application to Earth gravity field modelling. J. Comput. Phys., 398, 108876, doi: 10.1016/j.jcp.2019.108876.

Fašková Z., Čunderlík R., Mikula K., 2010: Finite element method for solving geodetic boundary value problems. J. Geod., 84, 2, 135-144, doi: 10.1007/s00190-009-03 49-7.

Förste Ch., Bruinsma S. L., Abrikosov O., Lemoine J.-M., Marty J. Ch., Flechtner F., Balmino G., Barthelmes F., Biancale R., 2014: EIGEN-6C4 - The latest combined global gravity field model including GOCE data up to degree and order 2190 of GFZ Potsdam and GRGS Toulouse. GFZ Data Services, doi: 10.5880/icgem.2015.1.

Grafarend E. W., 1989: The geoid and the gravimetric boundary-value problem. Rep. 18, Dept. Geod., The Royal Institute of Technology, Stockholm.

Klobušiak M., Leitmannová K., Ferianc D., 2005: Realization of obligatory transformation between national coordinates and height reference system into ETRS89 (Realizácia záväzných transformácií národných referenčných súradnicových a výškového Systému do Európskeho Terestrického Referenčného Systému 1989). http://www . etrs.sk/HELP/Transformacie/TATRY $\% 202005 \% 20-\% 20$ Jednotny $\% 20$ prechod $\% 20$ naro dnych\%20RsaVS\%20do\%20ETRS89.htm (in Slovak).

Koch K. R., Pope A. J., 1972: Uniqueness and existence for the geodetic boundary value problem using the known surface of the earth. Bull. Géod., 106, 467-476, doi: 10.1007/BF02522053.

Hirt C., Claessens S. J., Fecher T., Kuhn M., Pail R., Rexer M., 2013: New ultrahighresolution picture of Earth's gravity field. Geophys. Res. Lett., 40, 16, 4279-4283, doi : 10.1002/grl.50838.

Macák M., Čunderlík R., Mikula K., Minarechová Z., 2015: An upwind-based scheme for solving the oblique derivative boundary-value problem related to physical geodesy. J. Geod. Sci., 5, 180-188, doi : 10.1515/jogs-2015-0018.

Majkráková M., Papčo J., Zahorec P., Droščák B., Mikuška J., Marušiak I., 2016: An analysis of methods for gravity determination and their utilization for the calculation of geopotential numbers in the Slovak national leveling network. Contrib. Geophys. Geod., 46, 3, 179-202, doi: 10.1515/congeo-2016-0012.

Marušiak I., Mikuška J., Papčo J., Zahorec P., Pašteka R., 2015: CBA2G (Complete Bouguer Anomaly To Gravity), program for calculation of the gravity acceleration from complete Bouguer anomaly, program guide. Manuscript, G-trend Ltd.

Medla M., Mikula K., Čunderlík R., Macák M., 2018: Numerical solution to the oblique derivative boundary value problem on non-uniform grids above the Earth topography. J. Geod., 92, 1-19, doi: 10.1007/s00190-017-1040-z.

Mojzeš M., Janák J., 1999: New gravimetric guasigeoid of Slovakia. Boll. di Geofis. Teor. ed Appl., 40, 3-4, 211-217.

Mojzeš M., Janák J., Papčo J., 2006: Improvement of the gravimetric model of quasigeoid in Slovakia. Newton's Bull., 3, 28-32. 
Pašteka R., Zahorec P., Kušnirák D., Bošanský M., Papčo J., Szalaiová V., Krajňák M., Marušiak I., Mikuška J., Bielik M., 2017: High resolution Slovak Bouguer gravity anomaly map and its enhanced derivative transformations: New possibilities for interpretation of anomalous gravity fields. Contrib. Geophys. Geod., 47, 2, 81-94, doi : 10.1515/congeo-2017-0006.

Sánchez L., Čunderlík R., Dayoub N., Mikula K., Minarechová Z., Šíma Z., Vatrt V., Vojtíšková M., 2016: A conventional value for the geoid reference potential $W_{0}$. J. Geod., 90, 9, 815-835, doi: 10.1007/s00190-016-0913-x.

Valkko M., Mojzeš M., Janák J., Papčo J., 2008: Comparison of two different solutions to Molodensky's G $\mathrm{H}_{1}$ term. Studia Geophys. et Geod., 52, 1, 71-86, doi: 10.1007/s11 200-008-0006-2.

Zahorec P., Marušiak I., Mikuška J., Pašteka R. Papčo J., 2017a: Numerical Calculation of Terrain Correction Within the Bouguer Anomaly Evaluation (Program Toposk), (chapter 5). pp. 79-92. In: Pašteka R., Mikuška J., Meurers B. (Eds.): Understanding the Bouguer Anomaly: A Gravimetry Puzzle, Elsevier, ISBN 978-0-12-812913-5, doi : 10.1016/B978-0-12-812913-5.00004-X.

Zahorec P., Pašteka R., Mikuška J., Szalaiová V., Papčo J., Kušnirák D., Pánisová J., Krajňák M., Vajda P., Bielik M., Marušiak I., 2017b: National Gravimetric Database of the Slovak Republic (chapter 7) pp. 113-125. In: Pašteka R., Mikuška J., Meurers B. (Eds.): Understanding the Bouguer Anomaly: A Gravimetry Puzzle, Elsevier, ISBN 978-0-12-812913-5, doi : 10.1016/B978-0-12-812913-5.00006-3. 